\title{
A RE-EXAMINATION OF THE EFFECT OF MONETARY REWARD AND PUNISHMENT ON FIGURE-GROUND PERCEPTION
}

\author{
BY IRVIN ROCK AND FREDERICK S. FLECK *
}

\author{
The Graduate Faculty of Political and Social Science, New School for Social Research
}

\section{INTRODUCTION}

In view of the increasing interest in the relationship between cognitive and conative processes $(5)$, it is important at this time to make sure that the results of experiments reported are reliable in the sense of being duplicable. Recently, Carter and Schooler (2) repeated the now well-known experiment by Bruner and Goodman (I) in which rich and poor children judged the size of coins. Their results did not confirm the findings of Bruner and Goodman as regards perceptual differences between the two groups, so that it is now far from certain that the need for valued objects operates to increase their phenomenal size in direct perception, since otherwise the minor changes in procedure reported would not abolish the effect.

Another well-known experiment, by Schafer and Murphy (4), utilized an ambiguous (reversible) figure-ground drawing as a test stimulus. Subjects were shown single faces tachistoscopically many times, some of which were consistently rewarded and some consistently punished by giving or taking away money after every presentation. The $S s$ were simultaneously told the name of each face. In the test situation, rewarded and punished faces were combined so as to form an ambiguous situation in which either face could be seen as

* The authors wish to express their appreciation to Professors M. Henle and H. Wallach for their helpful suggestions concerning the experiment and preparation of the manuscript. figure, while the other presumably would go unnoticed as ground in the brief presentation. The hypothesis of autistic perception advanced by the authors held that the need to receive money (reward) and conversely the need not to lose money (punishment). would operate as determinants in selecting the particular figure perceived so that the previously rewarded one should be recognized more frequently than the previously punished one in the ambiguous situation. The results indicated a significantly greater identification of rewarded faces than punished faces in the first 16 test trials. Although 32 test trials were given to each $S$, the authors did not include the latter 16 trials in their statistical computation because they believed that a set began to operate at this point in the test series, thereby introducing a factor alien to the hypothesis being investigated. It has been pointed out, however (3), that such a procedure is statistically unjustifiable. Nevertheless the results obtained for the first 16 trials cannot be ignored. In order to determine if the latter results were reliable, a repetition of the experiment with a larger number of $S$ s was considered necessary.

\section{Subjects}

The $S_{8}$ for the experiment were four males and nine females, all volunteers, ranging in age from $15: 8$ to $20: 6$, with an average age of $18: 00$. The youngest $S$ was in the fifth term of high school and the oldest in the second year of college. Nine of the $1_{3}$ Ss served as experimental and four as control $S_{8}$. 


\section{Procedure}

The procedure of Schafer and Murphy (4) was followed as closely as possible, so that only a summary will be presented here. Certain minor changes will also be noted.

Training.-The training consists of 100 tachistoscopic presentations, 25 of each of four different semi-circular profile faces (4, Fig. 1, p. 336), in random order. Just before each presentation, $S$ is told the name of the face, and instructed to repeat the name-aloud when the face is shown. He is then told to take or return the appropriate amount of money (either two or four cents) that he wins or loses, - Each experimental $S$ is told in advance that when either one of two of the four faces is shown, he will receive money and that when either one of the remaining two faces is shown he will lose money, In order to create the impression that $S$ in some way determines what face will-next be shown-and, therefore, his reward or punishment-he is further instructed to guess a number from one to four before each face is shown. . During the first eight trials only, the further precaution is introduced of pointing out to $S$ the appropriate one of four drawings of the faces placed before him =which looks like the face he will next be shown by tachistoscope. The drawings were made to look like the training faces, but were 'improved' in the sense that they were 'better' faces and, therefore, absolutely non-reversible.

To summarize, the procedure included the following steps: 1 . $S$ guesses a number from one to four. 2. $E$ points to the appropriate 'help' face. 3. $E$ announces the name of the face to be shown by saying, e.g., "B." 4. The figure is shown tachistoscopically. 5. $S$ repeats the name of the face-e.g." "B." 6. $E$ indicates the amount of money won or lost-e.g., "You win two cents," and remits. Step 2 is eliminated after the eighth trial of the training series.

After the 5oth trial, a five-min. rest period is introduced. After the 8oth trial, the $S$ is told that during the remaining presentations new and unfamiliar faces might be shown in order to see if he has learned the faces and their names and that he will be penalized to cento if he does not say "wrong" when the $E$ announces such a face with the name of one of the four training faces. Actually, only one such face is introduced after the $93 \mathrm{rd}$ trial and was sufficiently different from the training faces to be unmistakable if the $S$ really knew the faces by that time. Whereas. Schafer and Murphy report that all Ss immediately recognized this figure as strange (and pre-

1 A copy of the full procedure, including instructions to $S s$, used in the present experiment is available on request from the authors. sumably did not respond with "strange" to any of the other faces after the 8oth trial), one of our $S s$ incorrectly repeated " $B$ " when shown the new face. In addition, most of our Ss said "strange" to several of the training faces after the 8oth trial. The latter $S_{8}$ were not penalized 10 cents and no reward or punishment was announced in such instances. The $S$ who called the new face "B," was, however, penalized Io cents.

The distribution of the rewarded and punished faces for the different $S s$ was as follows: of the nine experimental $S s$, five were rewarded when shown Face $A$ and Face $D$, and punished when shown Face $B$ and $C$. The remaining four $S$ were rewarded when shown Face $B$ and Face $C$ and punished when shown Face $A$ and Face D.2 (Face A-right-pointing-and $\mathrm{B}$-left-pointing -comprised the A-B ambiguous situation; Face $C$-right-pointing-and D-left-pointing comprised the C-D ambiguous situation). This distribution was intended to control the possible influence of structural and positional differences.

The procedure is the same in all respects for the control group except that all reference to reward and punishment is eliminated.

Post-training.-The post-training series follows after a five-min. rest period, It consists of 32 tachistoscopic presentations, 16 of each of two ambiguous (reversible) figure-ground drawings (4, Fig. 2, p. 337) in random order. Each ambigwous situation consists of one previously rewarded and one previously punished training face merged within a full circle so as to share the same contour. The $S$ is instructed to respond with the correct name of the face he sees or, since he was told that some of the faces to be presented would be strange, to say " $X$ " if he does not recognize a face as one of the four shown previously. After every presentation of an ambiguous test figure, either one or the other of two new figures is shown; depending upon $S^{\prime}$ s previous response. Each of these figures (4, Fig. 3, p. 338, here called $\mathrm{E}$ and $F$ ) resembles the ambiguous test figures in that it contains a profile line within a circle, but differs from them in that it contains only one 'good' face. If the $S$ 's previous response is a left-pointing training face, then it is followed by the new face which is necessarily right-pointing $(E)$, and vice versa. This precaution was introduced in order to prevent the development of any kind of direction set in the post-training series. Since one or the other of the new figures followed every presentation of an ambiguous test figure

2 Actually only six of the nine experimental Ss learned the names of the faces, so that the results of the other three $S s$ were not included in the statistical comparison. Of these six $S 8$, an equal number were rewarded to $F$ aces $A$ and $D$ and to $B$ and $C$. 
except the last, there was a total of 63 post-training trials consisting of 16 of each of the two ambiguous figures and 31 new or 'set-breaking' figures. The procedure for the post-training series is the same for experimental and control groups.

In the present experiment, certain minor changes or additions in procedure were introduced as follows:"

I. In order to alleviate feelings of nervousness, the $S 8$ were put at ease at the outset by explaining that this was not to be a test of any kind.

2. Instructions to $S \&$ were always read twice in order to insure full understanding of their task.

3. The experimental Ss were given their 'winnings' directly after the end of the training series.

4. In order to facilitate learning and to eliminate possible affective connotations of familiar names, the letter names $A, B, C$, and $D$ were used as. the names of the four training faces.

5. In the post-training series, $S$ was given the additional alternatives of responding with a question-mark if he felt he had no idea what face he had been shown, or of responding with a face name or "X" plus a question-mark if he thought he knew but wasn't really certain. As it turned out, most $S_{s}$ either forgot the instructions regarding the use of the question-mark or preferred to guess without indicating they were guessing. That this was the case is clear since very few question-mark responses were given despite the fact that the $\mathrm{Ss}_{\mathrm{s}}$ ' behavior and subsequent admissions indicated that very frequently they were quite uncertain of what they had seen.

6. Certain difficulties developed with the procedure described above of following each ambiguous situation with a 'set-breaking' figure. Many $S 8$ called $A-B$ or C-D figures "X." Consequently, since it was not clear whether the $S$ saw the left or right profile as a strange face, is was not certain whether then to show the $E$ or F 'set-breaking' figure. After such cases, an attempt was made to equalize the number of $\mathbf{E}$ and $F$ figures shown. Occasionally, an $S$ called an $A-B$ figure $C$ or $D$ or a $C-D$ figure $A$ or $B$. In such cases it was assumed that the face seen was correctly localized so that, e.g., a "C" response to an $A-B$ figure was followed by the $F$ figure since $C$ faced to the right and $F$ to the left. It also frequently happened that an $S$ called the $E$ or $F$ figure $A, B, C$, or $D$.

7. In order to determine whether or not the $S$ s had actually learned the names of the four

8 In some instances it is not certain whether these were actually modifications, since the description of the procedure employed by Schafer and Murphy is not explicit on all points. training faces, a learning test was introduced after the experiment proper was over. It consisted of showing the single faces again-with appropriate instructions-until $S$ achieved ro consecutive errorless trials or until it was clear that $S$ did not know the correct name of each of the four faces. Schafer and Murphy did not employ any such independent test of learning beyond the single catch test trial described above, presumably assuming that if an $S$ had not learned the names of the faces during training it would be revealed by his responses during the post-training series.

8. A post-experimental interview was included in the present experiment consisting of a series of questions concerning $S$ 's experiences during the training and post-training series, particularly as regards his reaction to the monetary reward and punishment, the operation of preferences if any, and his awareness or lack of awareness of more than one face in the reversible test figures.

9. In the present experiment the tachistoscope consisted of a shutter set for a $\mathbf{s - s e c}$. exposure mounted in front of an opaque projector behind and slightly to one side of $S$. (Schafer and Murphy used a Whipple tachistoscope also set for a t-gec. exposure. Their figures were two to three in. in diameter at a distance of about I8 in. from the S.4) The projector cast an image I 2 in. in diameter. $S$ was seated at a distance of approximately 54 in. from a white paper screen mounted on the wall. Half of the $S$ s sat slightly to the left and half slightly to the right of the screen.

\section{Results}

Experimental group.-Only six of the nine experimental $S$ s demonstrated by ro consecutive errorless trials in the final test of learning that they could correctly identify each of the four training faces by name. Since the only criterion of what an $S$ perceives in the test series with ambiguous figures is the name he announces, one cannot tell what he is perceiving in that situation if he does not know the correct name for each face. Consequently, only the results for the six $S$ s who did learn the names of the faces will be considered. The fact, however, that three of the nine

- These data were supplied in a personal communication by Dr. Schafer. 
TABLE I

Number of Rgsponses to Post-Trainino Test Figures: Entire Series Expertaental Group

(See Rzsults for meaning of symbols.)

\begin{tabular}{|c|c|c|c|c|c|c|c|c|c|c|c|c|c|c|}
\hline \multirow[b]{2}{*}{ Condition } & \multirow[b]{2}{*}{ Subject } & \multicolumn{6}{|c|}{$\begin{array}{l}\text { Responses to } A-B \\
\text { and } C-D \text { Figures }\end{array}$} & \multicolumn{4}{|c|}{$\begin{array}{l}\text { Responses to } E \\
\text { and } \mathrm{E} \text { Figures }\end{array}$} & \multicolumn{3}{|c|}{ Total Number of: } \\
\hline & & $\mathbf{R}$ & $\mathbf{P}$ & $\mathrm{x}$ & $?$ & $\mathbf{M}$ & $N$ & $\mathbf{x}$ & $\mathbf{M}$ & $?$ & $N$ & $\left|\begin{array}{c}\text { Correct } \\
\text { Responses }\end{array}\right|$ & $\begin{array}{l}\text { Incorrect } \\
\text { Plus Ques. } \\
\text { tiono Mark } \\
\text { Responses }\end{array}$ & $N$ \\
\hline$A$ and $D+$ & $\begin{array}{l}\text { Josephine } \\
\text { Joel } \\
\text { Lois }\end{array}$ & $\begin{array}{r}14 \\
10 \\
7\end{array}$ & $\begin{array}{r}2 \\
1 \\
16\end{array}$ & $\begin{array}{r}5 \\
14 \\
6\end{array}$ & $\begin{array}{l}0 \\
0 \\
2\end{array}$ & $\begin{array}{r}11 \\
7 \\
1\end{array}$ & $\begin{array}{l}32 \\
32 \\
32\end{array}$ & $\begin{array}{r}14 \\
0 \\
22\end{array}$ & $\begin{array}{r}17 \\
31 \\
8\end{array}$ & $\begin{array}{l}0 \\
0 \\
I\end{array}$ & $\begin{array}{l}3 \mathrm{I} \\
3 \mathrm{I} \\
3 \mathrm{I}\end{array}$ & $\begin{array}{l}30 \\
11 \\
45\end{array}$ & $\begin{array}{l}33 \\
52 \\
18\end{array}$ & $\begin{array}{l}63 \\
63 \\
63\end{array}$ \\
\hline $\begin{array}{l}B \text { and } C+ \\
A \text { and } \\
D-\end{array}$ & $\begin{array}{l}\text { Lenore } \\
\text { Michael } \\
\text { Ernest } \\
\text { Sum }\end{array}$ & $\begin{array}{r}10 \\
21 \\
8 \\
70\end{array}$ & $\begin{array}{r}18 \\
9 \\
18 \\
64\end{array}$ & $\begin{array}{r}2 \\
0 \\
5 \\
32\end{array}$ & $\begin{array}{l}2 \\
2 \\
0 \\
6\end{array}$ & $\begin{array}{l}0 \\
0 \\
1 \\
20\end{array}$ & $\begin{array}{r}32 \\
32 \\
32 \\
192\end{array}$ & $\begin{array}{r}27 \\
29 \\
31 \\
123\end{array}$ & $\begin{array}{l}3 \\
0 \\
0 \\
59\end{array}$ & $\begin{array}{l}1 \\
2 \\
0 \\
4\end{array}$ & $\begin{array}{c}3 \mathrm{I} \\
3 \mathrm{I} \\
3 \mathrm{I} \\
186\end{array}$ & $\begin{array}{r}55 \\
59 \\
57 \\
257\end{array}$ & $\begin{array}{r}8 \\
4 \\
6 \\
121\end{array}$ & $\begin{array}{r}63 \\
63 \\
63 \\
378\end{array}$ \\
\hline
\end{tabular}

experimental $S s$ and one of the four control $S s$ failed to learn the names of the faces is, in itself, of interest; since Schafer and Murphy do not report any such cases.

The results for the six $S s$ are given in Table I. The responses to the ambiguous $\mathrm{A}-\mathrm{B}$ or $\mathrm{C}-\mathrm{D}$ figures are indicated in terms of the number of times each $S$ responded with the name of a previously rewarded face ( $R$, column 3) and with the name of a previously punished face ( $P$, column 4). Column 5 indicates the number of times each $S$ called the A-B or $C-D$ figure strange (X). Such responses are, of course, wrong. Column 6 shows the number of times each $S$ responded to the A-B or C-D figures with a question mark. ${ }^{5}$ Column 7 gives the total number of incorrect responses $(M=$ mistakes) to the $A-B$ and $C-D$ figures excluding $X$ responses. Thus, responses of A or B to the $C-D$ figure and $C$ or $D$ to the

In those few caises where the $S$ gave an $A$, $B, C, D$, or $X$ response plus a question mark it was tallied as $A, B, C, D$, or $X$, respectively. Thus "C?" was counted as a $C$ response for the trial in question.
A-B figure are included. In column 8 the total number of responses is presented. The next three columns indicate the distribution of $\mathrm{X}, \mathrm{M}$, and ? responses, respectively, for the $E$ and F figures. This information is included here in order to give the full picture of how each $S$ responded to the entire 63 test trials. An X response here is, of course, correct. An $M$ response implies that the $S$ called the $E$ or $F$ figure $A, B, C$, or $D$. The next to the last two columns summarize the foregoing data in terms of total number of correct responses as against the total number of incorrect plus question-mark responses for all 63 trials. The total number of correct responses is derived by adding the number of $R$ and $P$ responses to the ambiguous figures to the number of $X$ responses to the $E$ and $F$ figures. All other responses are not correct. These figures, although not immediately relevant to the main result of $R$ vs. $P$ responses, are included because they point up the fact that although all six $S s$ had learned the names of the faces, there nevertheless remained a great deal of uncertainty, 
confusion and guesswork in the posttraining test series. By consulting the last row of sums it is seen that of a total of 378 trials, 121 or roughly one third of all the responses were incorrect. This result in itself is in striking contrast to the results of Schafer and Murphy where very few incorrect responses were given, although these authors do not indicate what the responses were to the 'setbreaking' figures.

As is indicated in Table $I$, for the two amibguous figures there was a total of 70 responses of names of faces previously rewarded as against a total of 64 responses of names of faces previously punished. The $\chi^{2}$ for this difference is .268 and $P<.7$. Hence, unlike the findings of Schafer and Murphy, our data indicate no reliable difference between the number of rewarded and punished faces perceived in the ambiguous figures. Analysis of the results for the different $S$ s reveals that three of the six $S$ s perceived more punished than rewarded faces and three perceived more rewarded than punished faces. Thus, there is not any consistent trend in our data to support the conclusions of the previous authors.
A comparison of the two ambiguous situations, considered separately, is presented in Table II. As is indicated in the bottom row of sums, in the A-B situation, a total of 23 rewarded faces and 40 punished faces was perceived. The $x^{2}$ for this difference is 4.6 and $P<.05$. Thus, there is a significantly greater tendency to see punished as against rewarded faces in the $A-B$ ambiguous situation. On the other hand, a total of 47 rewarded faces and 24 punished faces was perceived in the C-D situation. The $x^{2}$ for this difference is 7.4 and $\mathrm{P}<$.or. Hence, there is a significantly greater tendency to see rewarded as against punished faces in the C-D ambiguous situation. Since the results for the two situations, considered separately, point in opposite directions, such fractionation certainly does: not support the over-all thesis of autistic perception of previously rewarded figures. This result is again quite different from that reported by Schafer and Murphy where both the A-B and C-D situations showed a superiority of rewarded over punished faces perceived. On the other hand, the fact that in our data both sets of differences were significant, requires some

TABLE II

Comparison of Responses to the A-B and C-D Situations: Entire Series Experimental Group

(See Resurts for meaning of symbols.)

\begin{tabular}{|c|c|c|c|c|c|c|c|c|c|c|c|c|c|}
\hline \multirow{2}{*}{ Condition } & \multirow{2}{*}{ Subject } & \multicolumn{6}{|c|}{ Responses to A-B Figure } & \multicolumn{6}{|c|}{ Responses to C-D Figure } \\
\hline & & $\mathbf{R}$ & $\mathbf{p}$ & $\mathbf{x}$ & $?$ & $\mathbf{M}$ & $N$ & $\mathbf{R}$ & $P$ & $\mathbf{x}$ & $?$ & $\mathbf{M}$ & $N$ \\
\hline $\begin{array}{l}A \text { and } D+ \\
B \text { and } C-\end{array}$ & $\begin{array}{l}\text { Josephine } \\
\text { Joel } \\
\text { Lois }\end{array}$ & $\begin{array}{l}3 \\
1 \\
1\end{array}$ & $\begin{array}{r}0 \\
0 \\
15\end{array}$ & $\begin{array}{r}3 \\
14 \\
0\end{array}$ & 0 & $\begin{array}{r}10 \\
1 \\
0\end{array}$ & $\begin{array}{l}16 \\
16 \\
16\end{array}$ & $\begin{array}{r}\mathrm{Ir} \\
9 \\
6\end{array}$ & $\begin{array}{l}2 \\
1 \\
1\end{array}$ & $\begin{array}{l}2 \\
0 \\
6\end{array}$ & 2 & $\begin{array}{l}1 \\
6 \\
1\end{array}$ & $\begin{array}{l}16 \\
16 \\
16\end{array}$ \\
\hline $\begin{array}{l}B \text { and } C+ \\
A \text { and } D-\end{array}$ & $\begin{array}{c}\text { Lenore } \\
\text { Michael } \\
\text { Ernest } \\
\quad \text { Sum }\end{array}$ & $\begin{array}{r}4 \\
11 \\
3 \\
23\end{array}$ & $\begin{array}{r}10 \\
4 \\
11 \\
40\end{array}$ & $\begin{array}{r}I \\
0 \\
2 \\
20\end{array}$ & 3 & $\begin{array}{l}0 \\
0 \\
0 \\
\mathbf{I}\end{array}$ & $\begin{array}{l}17 \\
16 \\
16 \\
97\end{array}$ & $\begin{array}{r}6 \\
10 \\
5 \\
47\end{array}$ & $\begin{array}{r}8 \\
5 \\
7 \\
24\end{array}$ & $\begin{array}{r}1 \\
0 \\
3 \\
12\end{array}$ & $\begin{array}{l}0 \\
1 \\
0\end{array}$ & $\begin{array}{l}0 \\
0 \\
1 \\
9\end{array}$ & $\begin{array}{l}15 \\
16 \\
16\end{array}$ \\
\hline
\end{tabular}


TABLE III

Number of Responses to Post-Training Test - Figures: First 16 Trials Experimental Group

(See Resurrs for meaning of symbols.)

\begin{tabular}{|c|c|c|c|c|c|c|c|c|c|c|c|}
\hline \multirow{2}{*}{ Condition } & \multirow{2}{*}{ Subject } & \multicolumn{6}{|c|}{ Responses to $A-B$ and $C-D$ Figures } & \multicolumn{4}{|c|}{ Responses to $\mathrm{E}$ and $\mathrm{F}$ Figures } \\
\hline & & $\mathbf{R}$ & $\mathbf{P}$ & $\mathbf{x}$ & 3 & $\mathbf{M}$ & $N$ & $\mathbf{x}$ & $\mathbf{M}$ & $?$ & $N$ \\
\hline$A$ and $D+$ & $\begin{array}{l}\text { Josephine } \\
\text { Joel } \\
\text { Lois }\end{array}$ & $\begin{array}{l}5 \\
5 \\
3\end{array}$ & $\begin{array}{l}2 \\
1 \\
8\end{array}$ & $\begin{array}{l}4 \\
7 \\
3\end{array}$ & $\begin{array}{l}0 \\
0 \\
2\end{array}$ & $\begin{array}{l}5 \\
3 \\
0\end{array}$ & $\begin{array}{l}16 \\
16 \\
16\end{array}$ & $\begin{array}{r}8 \\
0 \\
13\end{array}$ & $\begin{array}{r}8 \\
16 \\
3\end{array}$ & 0 & $\begin{array}{l}16 \\
16 \\
16\end{array}$ \\
\hline $\begin{array}{l}B \text { and } C+ \\
A \text { and } D-\end{array}$ & $\begin{array}{l}\text { Lenore } \\
\text { Michael } \\
\text { Ernest }\end{array}$ & $\begin{array}{r}4 \\
12 \\
5\end{array}$ & $\begin{array}{l}9 \\
4 \\
8\end{array}$ & $\begin{array}{l}\text { I } \\
0 \\
3\end{array}$ & $\begin{array}{l}2 \\
0 \\
0\end{array}$ & $\begin{array}{l}0 \\
0 \\
0\end{array}$ & $\begin{array}{l}16 \\
16 \\
16\end{array}$ & $\begin{array}{l}14 \\
14 \\
16\end{array}$ & $\begin{array}{l}2 \\
0 \\
0\end{array}$ & $\begin{array}{l}0 \\
2 \\
0\end{array}$ & $\begin{array}{l}16 \\
16 \\
16\end{array}$ \\
\hline & Sum & 34 & 32 & 18 & 4 & 8 & 96 & 65 & 29 & 2 & 96 \\
\hline
\end{tabular}

explanation. In examining the individual results for both situations combined (Table I), it appears that, although the total number of rewarded and punished faces perceived is about equal, this total derives from highly unequal distributions for each $S$. Thus, e.g., Josephine perceived 14 rewarded and 2 punished faces, Lois 16 punished and 7 rewarded faces, etc. Pursuing this analysis further, one finds that such disparities for each $S$ derive from the particular dominance of response of either one rewarded face or one punished face. Thus, of Josephine's I4 responses to rewarded faces, II were to Face $D$ and only 3 to Face A; of Lois' 16 responses to punished faces, 15 were to Face $B$ and only $I$ to Face C (see Table II). Hence, it is suggested that the significant differences found by comparing rewarded to punished responses in the $A-B$ and C-D situations separately are, in a way, artifacts, resulting from the greater dominance of the punished face for several $S_{8}$ in the A-B situation and of the rewarded face for several So in the C-D situation. The fact of such responsedominance is discussed further in the following section.
The results for the first 16 trials considered alone are presented in Table III. As is indicated in the bottom row of sums, 34 responses of rewarded faces and 32 of punished faces were given to the $A-B$ and $C-D$ ambiguous situations during the first 16 presentations of these figures. The $x^{2}$ for the difference is .06 and $P<.8$. Hence, according to the present data, regardless of whether some kind of set or perseverating tendency developed after the 16 th trial, the hypothesis of autistic perception of previously rewarded faces is not confirmed by the results of the first 16 trials. Furthermore, of the six $S s$, the same three who gave more 'punished' than 'rewarded' responses for the entire series gave more 'punished' than 'rewarded' responses for the first 16 ambiguous presentations.

Control group.-In view of the possibility of competition between structural and conative influences, the use of control $S \&$ who are neither rewarded nor punished in the training period becomes important. 'Schafer and Murphy included one control $S$ but did not report the results obtained. Of the four control $S$ s included in the present study, only three demonstrated that 
TABLE IV

Number of Responses to Post-Training Test Figures: Entire Series Control Group

(See Results for meaning of symbols.)

\begin{tabular}{|c|c|c|c|c|c|c|c|c|c|c|c|c|c|c|c|}
\hline \multirow[b]{2}{*}{ Subject } & \multicolumn{8}{|c|}{ Responses to: A-B Fig. and C-D Fig. } & \multicolumn{4}{|c|}{$\begin{array}{l}\text { Responses to } \\
\mathrm{E} \text { and } \mathrm{F} \text { Figs. }\end{array}$} & \multicolumn{3}{|c|}{ Total Number of: } \\
\hline & A & B & c & D & $\mathrm{x}$ & $?$ & $\mathbf{M}$ & $N$ & $\mathrm{x}$ & $\mathbf{M}$ & $?$ & $N$ & $\begin{array}{c}\text { Correct } \\
\text { Responses }\end{array}$ & $\begin{array}{l}\text { Incorrect } \\
\text { Plus Ques- } \\
\text { tion-Mark } \\
\text { Responses }\end{array}$ & $N$ \\
\hline $\begin{array}{l}\text { Helen } \\
\text { Edith } \\
\text { Marie }\end{array}$ & $\begin{array}{r}0 \\
6 \\
12\end{array}$ & $\begin{array}{l}0 \\
0 \\
3\end{array}$ & $\begin{array}{r}14 \\
3 \\
0\end{array}$ & $\begin{array}{l}2 \\
0 \\
4\end{array}$ & $\begin{array}{l}10 \\
17 \\
13\end{array}$ & $\begin{array}{l}0 \\
0 \\
0\end{array}$ & $\begin{array}{l}6 \\
6 \\
0\end{array}$ & $\begin{array}{l}32 \\
32 \\
32\end{array}$ & $\begin{array}{l}12 \\
14 \\
17\end{array}$ & $\begin{array}{l}16 \\
17 \\
14\end{array}$ & $\begin{array}{l}3 \\
0 \\
0\end{array}$ & $\begin{array}{l}3 I \\
3 I \\
3 I\end{array}$ & $\begin{array}{l}28 \\
23 \\
36\end{array}$ & $\begin{array}{l}35 \\
40 \\
27\end{array}$ & $\begin{array}{l}63 \\
63 \\
63\end{array}$ \\
\hline Sum & 18 & 3 & 17 & 6 & 40 & $\circ$ & 12 & 96 & 43 & 47 & 3 & 93 & 87 & I02 & 189 \\
\hline
\end{tabular}

they had learned the names of the faces in the final test. Table IV gives the results for these three $S s$ in terms of the number of correct $A$ and $B$ responses to the $A-B$ figure and the number of correct $C$ and $D$ responses to the $\mathrm{C}-\mathrm{D}$ figure. Also given are the total number of strange $(\mathrm{X})$, question-mark (?), and incorrect (M) responses to the A-B and C-D situations, as well as the breakdown of responses to the $E$ and $F$ figures, as in Table I. The total number of correct as against incorrect plus questionmark responses to all 63 trials is given in the next to the last two columns. As is indicated in the bottom row of sums, there was a total of 18 ' $A$ ' and 3 ' $B$ ' responses to the $A-B$ situation, I7 ' $C$ ' and 6 ' $D$ ' responses to the C-D situation. These figures are, of course, too small to draw any reliable inferences concerning structural differences. It may be noted, however, that two of these three Ss gave a preponderance of responses to one of the two faces in one ambiguous situation, namely Helen with ${ }_{4} \mathrm{C}$ to $2 \mathrm{D}$ responses and Marie with $12 \mathrm{~A}$ to $3 \mathrm{~B}$ responses.

Of the total of 189 responses given by the three control $S s$ to the 63 trials, 87 were correct and 102 were either incorrect or question-mark responses. Thus, for the control Ss more than half of all the responses in the test situation were not correct despite the fact that these Ss shortly thereafter demonstrated by ro consecutive errorless trials that they did know the correct name for each face.

Interview.-By including an interview in preliminary experiments, certain facts emerged which otherwise would not have been ascertained. For example, several Ss reported having immediately seen both faces-or at least two faces-in many of the ambiguous presentations, while nevertheless responding with the name of only one face. ${ }^{6}$ Such a fact is important because it indicates that the verbal response need not always accurately describe the percept.

The data obtained from the post-experimental interviews can be summarized as follows: Only one of the six experimental $S$ s (Michael) actually experienced 'winning' and 'losing' money with any degree of involvement. All other Ss claimed that the money meant nothing to them but instead that they were anxious to "do well" and to learn what they were supposed to learn. Some $S \mathrm{~s}$

- This only occurred once for one $S$ and several times for another $S$ in the experiment proper. The reason for this difference, it is believed, is that a more accurate timing device was introduced. 
were actually insulted by the use of money as a reward and punishment and refused to take their 'winnings' afterward until the Es insisted. Thus, e.g., one $S$ in answer to the question "How did you feel about the money?" said, "It didn't make any difference, I just kept pushing it back and forth." Another $s$ said; "I was indifferent to it." When pressed further, he added: "Naturally everyone prefers to win, but in this case it didn't mean anything." Another $s$ said: "Yes, I wanted to figure out why I won it, not for the money itself but to get the formula of the numbers. The money didn't mean any thing. I was more interested in the facts behind it than the money itself."

The one $S$ who apparently was involved with the money gave 2I 'rewarded' and 9 'punished' responses to the $A-B$ and $C-D$ ambiguous situations in the post-training series. Thus, it is possible that for this $S$ the greater number of 'rewarded' as against 'punished' responses given to the ambiguous situations can be attributed to the selective influence of prior reward and punishment. On the other hand, during the interview he reported that during the post-training series he saw two faces on several occasions. He then went on to say:

I think I decided on one of the two at the beginning. Then when the same picture was flashed again, I gave that same anower; whether initially I was wrong or right. I had no better way of identifying them. I found it difficult to see them when in a complete circle.

In the case of all other experimental Ss, however, there is reason to doubt that the intended situation of reward and punishment existed. Not only did these $S$ s deny having experienced any reward or punishment but four $S$ s did not know which faces had been rewarded and which punished. One $S$ knew which was which for one ambiguous situation but not for the other. Furthermore, the four $S$ s who did not know which faces were rewarded and which punished did not even believe that certain faces were always rewarded and certain faces always punished. This is understandable in view of the fact that they were preoccupied during the learning series with learning the names of the faces and with trying to figure out the 'system' behind the number-guessing procedure. They did not attend to the relationship between a particular face and the fact that it was rewarded or punished. In view of these facts; if the reward and punishment were at all factors in creating differential attitudes towards the faces, they must have operated on a mechanical and nonconscious level.

Each experimental $S$ voiced a particular preference or dislike for one or moreof the faces. With the exception of Michael and Josephine, however, there is no clear relationship present between indicated preference and number of corresponding responses to the ambiguous situation. There is, however, for some $S_{s ;}$ a relationship between such stated preferences and the total number of times that particular face was given as a response-correctly or incorrectly-during all 63 trials. Joel, e.g., who said he preferred B, called every F Figure " $B$ " throughout the series. In fact, an $S$ 's indication of a preference may very well be the result of recalling his own responses during the post-training series. If this is true then such stated preferences are of little interpretive value since they would be more the result of, rather than a cause of, $s$ 's own responses.

There was only one case where anything like a volitional effort or expectation operated to influence the perceptual 'selection, according to the interviewprotocols. This was where the $S$ (Lois) maintained that she always looked for faces looking towards the left. This contention is -borne out by her results, since she saw $B$. 5 times and D six times whereas $A$ and $C$ were seen only once each.

\section{Discussion}

The results of this experiment do not substantiate the previous findings of Schafer and Murphy (4) that differential monetary reward and punish- 
ment influence the perception of faces in a reversible figure-ground situation. An analysis of the quantitative and qualitative data obtained suggests several reasons for the present findings, involving certain weaknesses and previously undetected aspects of the procedure followed.

I. There is reason to doubt that the monetary reward and punishment succeeded in establishing the intended attitudes towards the different faces. It is possible, of course, that such attitudes were created without $S$ being aware of it, so that it is difficult to demonstrate conclusively whether or not this prerequisite condition actually existed in both the original experiment and the present repetition of it.

2. Even if such attitudes towards rewarded and punished faces were successfully induced in training, however, or if it would be possible so to change the procedure that they would be induced, a purely statistical consideration of results is apt to be misleading. It was pointed out, e.g., that there was a considerable degree of uncertainty and confusion in the post-experimental test series, as is indicated by the large number of incorrect responses. Why should this be the case for $S \mathrm{~s}$ who subsequently demonstrate that they can correctly identify the four faces? The answer is, the authors believe, that the ambiguous figure containing the two faces is, as a whole, phenomenally something quite different from either one of these faces presented alone. Although most Ss did not perceive the two faces in the short exposure, still, the full circle with its dividing profile line is qualitatively different from the single closed figure of a face. The protocols of several Ss support this contention. Thus, e.g., Michael, as noted above, claimed he found it difficult to see the face when it was in a complete circle. Joel, in describing his preference for Face A said: "I could see it more easily, but in the full circle, I didn't recognize it frequently," Another $S$ referred to the "jumbled up" appearance of the ambiguous figures. The most conclusive evidence on this point, however, came from the reaction of several $S$ s when $E$ was explaining the purpose of the experiment after it was over. At that time, when $S$ was shown that two training faces were both present in the ambiguous figure, many $S$ s denied that they looked the same as the single faces even though they were both present for direct comparison. The reader can get some idea of such differences by comparing the single faces used in the training series with the faces in the ambiguous situations (4, Figs. I and 2, pp. 336, 337). Tachistoscopic presentation probably increases such phenomenal differences.

Another source of the difficulty in correctly identifying faces in the posttraining series is the introduction of the two new faces, $E$ and $F$. It will be recalled that in the training series, the mere instructions that new faces might be shown (after the 8oth trial) resulted in quite a few incorrect responses of "strange" to the A, B, C, and $D$ faces.

3. These facts, in turn, are related to another aspect of the results, namely the effect of the sequence of trials in the post-training test series. If the interpretation given above is correct, then the post-training series represents a situation where the previous learning is not necessarily immediately helpful. The relatively new appearance of all faces in the ambiguous setting implies that $S$ is not at all certain of what is being presented. A certain amount of guesswork is therefore involved at the outset for many Ss. 
After a while, however; all of the ambiguous and 'set-breaking' figures have been presented, so that $S$ can compare one with another from memory and arrive at a decision. The new global impression of the A-B Figure is certainly different from that of the $C-D$, $E$, or $F$ Figures, so that, in a sense, a new process of discriminative learning is going on in this series. Once decisions are reached as to how each figure is to be identified, the $S$ usually sticks to them for quite a number of trials, or, in some cases, for the remainder of the series even though he realizes he may be wrong throughout. There is, in other words, a certain consistency which develops in responding to a situation where there is no check on correctness or incorrectness after each trial. The writers suggest that this explanation accounts for the development of what Schafer and Murphy called a "set." If this explanation is correct, then one must be cautious about - statistical interpretations of the quantitative results of the posttraining series. Differential total scores would then not necessarily imply so and so many recognitions of one face vs. another, but rather consistent application of decisions as to which previously learned face most resembles which new global presentation. For this reason, a better, though practically infeasible, procedure would be to give, say, 100 Ss each one trial with each ambiguous situation in order to avoid the contaminating effect of early presentations of ambiguous figures upon subsequent ones. Of course such-a procedure would not eliminate the other difficulties with this experiment.

The evidence supporting the above interpretation derives from: $(\mathrm{r})$ the great number of errors-including consistently made errors-in the post-training series in the light of the subsequently demon- strated ability to distinguish the single faces when presented alone; (2) introspective reports of $S_{s}$ and like observations by the two Es indicating the phenomenal difference between faces seen in the two situations; (3) initial uncertainty in the post-training series indicated by delayed response, variations in responses, etc., followed by seemingly increased certainty and increased consistency of responses to each figure; (4) introspective reports by some $S$ s confirming the interpretation of an attempt at consistency after an initial period of uncertainty. The process, in many cases, may have been somewhat as follows: At first, when, e.g., the A-B Figure is presented, $S$ may, within the new global impression, perceive Face $A$ looking towards the right. If he calls this figure " $A$;" he may nevertheless have doubts as to its identity with the $A$ figure he had learned previously. The next time the A-B figure is shown, the global impression is now somewhat familiar, and is associated with the idea of " $\mathrm{A}$, facing right," derived from the previous trial with $A-B$, and so on. Furthermore, in the interim, he has seen other figures which he tentatively identifies as, e.g.; " $C$ " or " $X$," so that the comparison supports his initial assumption about "A." Although the initial 'selection' of one or the other of the two faces in an ambiguous figure may be determined by prior reward or punishment, there is no evidence of this in the results of this experiment. Certainly other factors also play a role in such determination. Once such a 'selection' is made, however, it tends to remain dominant for the reasons suggested above.

There were exceptions to this trend towards consistency of response to a given figure. Often an $S$ would change his response to a figure after having responded several times in succession previously with one face-name. If this happened, it was apt to affect his responses to the other figures in order to avoid obvious self-contradiction. This is actually another kind of 
consistency and again points up the fact that the response on one trial very much influenced responses on subsequent trials. There were, however, a great many other responses and sequences of responses which cannot be explained as instances of an attempt to be consistent following initial or subsequent decisions regarding the identification of the different faces. Many of these responses were no doubt instances of spontaneous figure-ground reversal.

It is regrettable that only the results for six experimental and three control $S s$ of the total of $\mathrm{r}_{3} \mathrm{Ss}$ initially participating, could be included in the data examined. It would be particularly valuable in any further experimentation of this type to use a larger number of control $S s$ in order to determine the relative influence of structural differences between faces.

\section{SUMMARY}

An experiment devised to test the hypothesis of autistic influence on figure-ground perception was repeated with nine experimental and four control Ss. The results can be summarized as follows:

r. Only six of the nine experimental $S s$ and three of the four control $S$ s actually learned the names of the training faces.

2. There was no significant difference between the total number of previously rewarded and of previously punished faces correctly identified in the ambiguous situations for the six experimental Ss. There were significant differences between the number of previously rewarded and previously punished faces correctly identified in each of the two ambiguous situations considered separately, but the differences were in opposite directions for the two situations. The difference between rewarded and punished faces identified was not significant for the results of the first half of the series of ambiguous figures considered alone.

3. A considerable number of mistakes was made in identifying the ambiguous figures.

4. Most Ss indicated that they did not experience the monetary reward and punishment as rewarding or punishing. Several $S$ s did not know which faces had been rewarded and which punished.

5. Evidence was cited to the effect that the faces composing the ambiguous figures appeared phenomenally different from the single faces when seen separately. It was suggested that this fact creates a condition of uncertainty during the series of ambiguous figures so that new learning processes are involved. The latter disturb the purity of this series as a test of differential figure-ground perception.

(Manuscript received for immediate publication October 2, 1950)

\section{RefERENCES}

I. Bruner, J. S., \& Goodman, C. C. Value and need as organizing factors in perception. J. abnorm. soc. Psychol., 1947, 42, 33-44.

2. Carter, L. F., \& Schooler, K. Value, need, and other factors in perception. Psychol. Reo., 1949, 56, 200-297.

3. Pastore, N. Need as a determinant of perception. J. Psychol., 1949, 28, 457-475.

5. Schafer, R., \& Murphy, G. The role of autism in a visual figure-ground relationship. J. exp. Psychol., 1943, 32, 335-343.

5. Srmposium. Interrelationships between perception and personality, Parts I and II. J. Personality, 1949, -18, September and December. 